\title{
Canadian Federation of Professional Foresters Association Brief on Herbicides in Forestry
}

The Canadian Federation of Professional Foresters Associations has drawn together and summarized the briefs prepared by its 5 members on herbicide and pesticide use in forestry. This compendium together with an executive summary focussing on herbicides has been presented to the Federal Ministers of Agriculture. Environment, Fisheries and Oceans, and Health and Welfare. The complete document is being distributed in British Columbia, Ontario, Quebec and New Brunswick by the respective provincial registered professional foresters groups. Distribution elsewhere in Canada is being undertaken by the CIF through its Sections. The main points of the CFPFA executive summary and the verbatim CFPFA recommendations follow:

\section{The Need for Herbicides in Forestry}

Controlled use of herbicides is essential to achieve the timber harvest targets set by the Canadian Council of Resource and Environment Ministers and provincial governments. The control of competing vegetation results in dramatic increases in forest productivity (by as much as 300 percent). Usually the most productive lands are also more prone to brushing in. We cannot afford to waste valuable copland growing weeds instead of trees.

Alternate means of preparing brushthreatened sites for tree planting and for carrying out weeding in young plantations are available and are used wherever possible. These include mechanical equipment, prescribed burning manual treatments, or a combination. However, in certain instances, none of these alternatives is feasible: mechanical scarification may favor other weed species; costs may be prohibitive: manual weeding is unsafe in dense weed tree cover; burning is not always ecologically viable and established commercial trees are often removed accidentally along with weed cover. In such cases the safe, regulated use of herbicides is mandatory if a commercial forest crop is to be established and/or maintained until it attains a free-growing state. Herbicide applications are as much as 15 times more cost effective than manual treatments. Herbicides act selectively, killing weed species without affecting commercial trees. If the forest manager has a variety of herbicides at his disposal, he can choose the one which will control the most competitive weed species with the mini- mum disturbance to other flora and fauna on the site. A greater variety of herbicides for forestry is required for more effective treatments and more selectively in weed eradication.

\section{Health and Safety}

Extensive research in Australia. New Zealand, the United Kingdom, Canada and the United States on the toxicity to humans of forestry herbicides has shown that, properly employed, herbicides can be used safely. In 1980, the American Medical Association's Advisory Panel on Toxic Substances stated that there is no conclusive evidence that the main herbicides required in forestry cause abnormalities, mutations or cancer in humans, nor do they cause human reproductive difficulties. There is no valid medical or scientific evidence that the herbicides required for forestry harm humans, animals or the environment if they are used in the recommended way and for the recommended purposes.

The hazard to the applicator or bystander from the proper use of registered forestry herbicides is no greater than that from an extremely large range of other industrial, agricultural and household products that are in common and undisputed use. Furthermore, the forest sites on which herbicides are used are usually distant from habitation, and access can be controlled during and immediately following application when necessary.

\section{Environmental Factors}

Herbicides have low toxicity to fish and wildlife. Because the areas and dosages involved are small, and application techniques sophisticated, the chance of wide contamination is small. Most forestry herbicides degrade quickly and/or are bound tightly in soils reducing contamination through run-off or other means. The sites on which herbicides are used have been disrupted by natural forces or harvesting. The rapid return of these sites to vigorous, young forests is frequently more beneficial to wildlife than extensive tracts of brush and weeds. The widely-held belief that most forest ecosystems are too delicate to sustain a herbicide treatment is simply not true. Many people also feel that herbicide treatment lowers the aesthetic appeal of the forest. However healthy crops of trees are aesthetically and recreationally more appealing to many than heavy brush cover.

To put forestry use of herbicides into perspective, about 75000 ha/year of Canada's forests are treated with herbicides. Agricultural treatments involve about $30000000 \mathrm{ha} /$ year. These figures do not take into account additional treatments for industrial, right-of-way and home use of herbicides. It is important to remember that agricultural usage mainly involves the same land being treated year after year. In forestry, only very small portions of the land base ever need herbicide treatment and when they do, applications only occur once or twice every 40-100 years. Only about one-half of one percent of the herbicides used in Canada each year are applied in forestry.

Canada's herbicide legislation and regulation is stringent and prudent. Chemicals are registered for the specific usage involved and applicators must be licensed in almost every province.

\section{Recommendations}

The Canadian Forestry Service (CFS), with the backing of other involved agencies, should take the lead role in a cooperative approach to forest herbicide usage, regulation and research by forest companies, chemical manufacturers, and government departments.

Provincial and federal government agencies must develop a co-ordinated approach toward forest herbicide regulation so that chemical registration and application permit procedures are safe, streamlined and in step.

The four involved federal departments must set up co-ordinated registration procedures for forestry and agriculture herbicides so that full registration could result after a common set of testing procedures is completed. While critically important to the industry, forestry usage of herbicides is so relatively small that it is often not economically feasible for herbicide manufacturers to get their agriculturally acceptable products registered for forestry use.

The currently fragmented herbicide research program for forestry must be better co-ordinated and focused.

Research efforts should concentrate on three areas:

- development of silvicultural systems which would reduce the need for herbicide applications (preventative techniques): 
- improvement of herbicide application methods to give maximum effectiveness while maintaining or reducing the current low risk levels to health and the environment; and

- development of more acceptable methods and chemicals for combating forest weeds.

The herbicide research capabilities and responsibilities of the CFS's Forest Pest Management Institute and regional research establishments must be significantly improved and expanded.

Research and registration programs should be co-ordinated with their counterparts in the United States, possibly through a bilateral, co-operative agreement.

There is a need for improved and standardized monitoring of herbicide applications, and training and certification of applicators.

An adequately and jointly funded education and relations program should be mounted under a committee comprised of the federal departments of Environment, Health and Welfare, Fisheries and Oceans, and Agriculture with a standing advisory board of industrial and governmental pesticide and communications experts. Provincial (or regional) subcommittees should be established in the same fashion, comprised of representatives of involved provincial government departments, regional CFS establishments, and involved companies.

The public review process is extremely important and necessary, but must be structured in a way that the public in its broadest sense is fully involved and fully briefed on the issues, choices, benefits and risks involved in forest herbicide projects.

Mechanical and manual weeding techniques should be preferred under suitable conditions where they will be effective and provided that socio-economic impacts of these labour intensive and publicly preferred treatments are positive. The higher costs of these treatments should be considered in the context of total government budgets (welfare and unemployment) for justification purposes.

Training and research in brush management and prevention should be increased in Canada's universities and technical schools

R.J. Bourchier Executive Director

\section{Forest Policy Issues and Developments}

\section{British Columbia}

Through the 1983-1988 Five Year Forest and Range Resource Program, the Government of the Province of British Columbia has set priorities of the Ministry of Forests to include "to reduce the size of the Ministry, to increase the role of the private sector, and to aid, enhance and support the economic recovery in the forest sector to the greatest possible degree". To assist in fulfilling this mandate, the Ministry of Forests has prepared a public discussion paper entitled "Forest Management Partnership Proposal - Tree Farm Licences"

\section{W. Young \\ Chief Forester Ministry of Forests Province of British Columbia}

\section{Erratum}

The October issue of the Forestry Chronicle carried on page 217 a statement by W.T. Foster. Deputy Minister with the Ontario Ministry of Natural Resources dealing with natural resources research. The statement as printed contains an unfortunate error in that the word "not" was inadvertently inserted in the last sentence of the fourth paragraph. This completely changes the meaning and says the Ministry should not generate or fund the production of knowledge. Mr. Foster is saying that direct generation of knowledge is not the Ministry's business but fuding it is. The correct fourth paragraph follows:

"With reference to the traditional roles of government, i.e. legislation, regulation and monitoring, I do not see the generation of scientific knowledge by the Ministry as a legitimate role in the present circumstances. The funding and direction of research so that specific knowledged is available to government does however fall within the traditional role of government."

W.B.G. Denyer

\section{New Working Groups?}

At the 75th meeting in Sault Ste Marie the possibility of forming two new working groups was discussed by the Executive and the Forest Science \& Technology Board. Suggestions have been received to form working groups in Forest Utilization and in Private Land Forestry. At present there are working groups in the following areas:

Forest Ecology

Forest Economics and Policy

Forest Education

Forest Entomology and Pathology

Forest Fire Control Science

Forest Harvesting

Forest Hydrology

Land Use Planning

Forest Landscape, Recreation and Tourism

Forest Management

Forest Measurement

Silviculture and Tree Improvement

Urban Forestry

Wildlife and Fish Habitat

International Forestry

The Executive is looking for an expression of opinion from the membership at large on the need for and usefulness of working groups in these two areas. You will recall that working groups are to provide a focus for members with a common interest; promote the production of articles and presentations for The Forestry Chronicle and annual meetings, and provide a pool of expertise in specific areas to conduct or help conduct special assignments to develop CIF/IFC positions, plan meetings etc.

Some working groups have been very active and others virtually inactive. The latter are being reviewed now for possible revitalization or abolition. It is important to create only groups that have a real purpose and can make a solid contribution to Institute affairs. Please send your thoughts on the wisdom of forming these Working groups to the Executive Director.

R.J. Bourchier 